\title{
Poética del yo en los dietarios de José Jiménez Lozano: Los tres cuadernos rojos
}

\author{
Ana CALVO REVILLA \\ Universidad CEU San Pablo \\ crevilla.ihum@ceu.es
}

\begin{abstract}
RESUMEN
Analizamos los principios poéticos que presiden la escritura de Los tres cuadernos rojos, el primer volumen de dietarios publicado por José Jiménez Lozano. Con ellos contribuye el escritor abulense a la vitalidad del género y se suma al continuum de la tradición literaria, ofreciendo los frutos de su diálogo constante con la cultura occidental. Nos detenemos especialmente en el análisis de dos de los núcleos temáticos que vertebran su pensamiento: las reflexiones teológicas, que muestran su interés por la dimensión espiritual y religiosa del hombre de su tiempo y las reflexiones históricas, que ofrecen una disección de la sociedad de su tiempo.
\end{abstract}

Palabras clave: José Jiménez Lozano, Los tres cuadernos rojos, cuaderno de notas, diario, tradición literaria.

\begin{abstract}
We analyze the poetical principles that govern the work Los tres cuadernos rojos, the first volume of diaries published by José Jiménez Lozano. Through these writings, the author, from Avila (Spain), contributes to the vitality of the genre and joins the writers who give continuum to literary tradition, by offering the fruits of his permanent dialogue with western culture. We especially take time to examine two of the core themes underpinning his thoughts: his theological reflections, that show his interest in the spiritual and religious dimension of contemporary man, and his historical reflections, which give a detailed depiction of society in his time.
\end{abstract}

Key words: José Jiménez Lozano, Los tres cuadernos rojos, notebooks, diary, literary tradition.

\section{SUMARIO}

1. Introducción. 2. El dietario en el escritor abulense. 3. Los tres cuadernos rojos: los demonios del hombre. 3.1. Complicidades lectoras y polifonías textuales. 3.2. Memoria 
passionis. 3.3. Controversias teológicas. Transversalidad del hecho religioso. 3.4. Ante el vértice de la nada o la muerte. 3.5. Apertura dialógica a la temporalidad. 4. Conclusiones

\section{Introducción}

José Jiménez Lozano, poeta singularísimo y narrador de hermosas historias que inquietan e hieren al lector, es un ensayista lúcido y dietarista pertinaz. Con este último quehacer se suma a la lista de escritores que desde época clásica (Julio César, Platón, Marco Aurelio, San Agustín, Dante, Montaigne, Rousseau, etc.) y especialmente desde finales del siglo XVIII (Stendhal, Amiel, Gide, Nietzsche, Kafka, Mann, Pavese, Jünger, Renard, Cioran, etc.) cultivaron la literatura del yo con manifestaciones diversas: autobiografías verdaderas o fingidas, cartas y epistolarios, memorias, libros de viajes, diarios, dietarios, etc. A pesar de que no han faltado quienes han subrayado la escasa tradición diarística ${ }^{1}$, en el ámbito de las letras hispánicas lo han cultivado escritores, de la talla de Juan Ruiz, fray Antonio de Guevara, Santa Teresa de Jesús, Lope de Vega, Quevedo, Gracián, Cadalso, etc. En el continuum de la tradición literaria a lo largo del siglo $\mathrm{XX}$ se ha ido observando una revitalización del género, una reprivatización literaria, que algunos críticos han atribuido al anquilosamiento de la literatura social y al resurgimiento de una estética literaria excesivamente volcada en sí misma y metaliteraria ${ }^{2}$. Así lo muestran las aportaciones de Pérez de Ayala, Maeztu, Azorín, Unamuno, Baroja, González Ruano, Pla, Chacel, Gil de Biedma, Umbral, Fuster, d'Ors, Ferrater Mora, etc., y, en las últimas décadas, Gimferrer, Trapiello, Juaristi, García Montero, Sánchez Ostiz, García Ortega, Muñoz Molina, Vila-Matas, Cercas, Marías, etc.

Los dietarios han ido conformando un género propio, diferenciado de los diarios. Con designaciones diversas -"Cuadernos" (El cuaderno gris, de Pla; Cuadernos de todo, de Martín Gaite; Cuaderno de Nautilus, de Muñoz Molina), "Dietarios" [Dietario de Madrid, de Pla; Dietario (1979-1980), de Gimferrer; Dietario voluble, de Vila-Matas], u otros títulos (Las horas solitarias, de Baroja; Vida del fantasma, de Marías; La inminencia, y Luna del sur, de García Montero; Lo que cuenta es la ilusión, de Vidal-Folch; El Robinson urbano, de Muñoz Molina)- acogen una escritura libre de estructura prefijada, donde el escritor vierte a través de sus anotaciones y apuntes reflexiones culturales, ideológicas o intelectuales; impresiones estéticas; sugerencias obtenidas tras lecturas diversas; anécdotas

\footnotetext{
${ }^{1}$ V. Tortosa (2000), p. 581.

2 J. C. Mainer (2000).
} 
cotidianas, derivadas de la vida social o política, etc., que pueden revestir cierta sistematización o no.

Diario y dietario son formas literarias que, encuadradas dentro de la literatura del yo, presentan algunas diferencias; si en los diarios predomina la confesión íntima y subjetiva, en los dietarios y memorias sobresale «la referencia a lo externo, el peso de lo ajeno o el trazado de un yo inmerso en un universo estético y cultural intensamente interiorizado ${ }^{3}$. Frente a la secuencialidad cronológica del diario, el escritor de dietarios no está sometido a la tiranía que impone el calendario. Aunque algunos críticos atribuyen a los dietarios un carácter confesional e hiperíntimo refugio frente a las inclemencias de la vida personal o pública ${ }^{4}-$, no parece este el rasgo predominante. Como sostiene Jordi Gracia, en España el dietario ha adoptado «un formato más aséptico y cauto, de cuño intelectual y literario, que parece impedir la averiguación obscena y cruda (unamuniana y kafkiana) de las cosas que da a veces el valor más alto a un diario» ${ }^{5}$. Comparte el dietario algunos rasgos con el ensayo, como la legitimidad del yo; el tono misceláneo; el carácter fragmentario y discontinuo ${ }^{6}$, que subraya la autonomía de cada anotación y propicia que su lectura pueda comenzar aleatoriamente, aunque sea la lectura continuada la que favorezca la obtención del sentido unitario del texto ${ }^{7}$. Con frecuencia acoge en su interior otras formas literarias: poemas, crónicas breves, reportajes periodísticos y se convierte en un magnífico «receptáculo» literario ${ }^{8}$.

Los dietarios proporcionan al escritor un espacio propicio para desplegar la huella que dejan en su espíritu los acontecimientos. Revisten interés especial para el lector, pues las anotaciones son leves susurros que proporcionan conocimiento del hombre de carne y hueso que los escribe.

\section{El dietario del escritor abulense}

José Jiménez Lozano ha venido publicando con regularidad sus dietarios. El primer volumen de la serie de seis ya publicados Los tres cuadernos rojos es publicado en la editorial Ámbito $(1986)^{9}$, seguido de Segundo abecedario (Anthropos, 1992), La luz de una candela (Anthropos, 1996), Los cuadernos de letra pequeña (Pre-Textos, 2003), Advenimientos (Pre-Textos, 2006) y Los cuadernos de Rembrandt (Pre-Textos, 2010). En el conjunto de su producción literaria no es un género residual o anecdótico, que deba ser desdeñado ni calificado

${ }^{3}$ A. Caballé (1996), p. 106.

${ }^{4}$ E. Bou (1993), p. 92.

${ }^{5}$ J. Gracia (2001), p. 149.

${ }^{6}$ Para estudiar los rasgos del género véase el estudio de José Carlos Mainer (1996).

${ }^{7}$ J. Gracia (2001), p. 153.

${ }^{8}$ B. Didier (1996), p. 39.

${ }^{9}$ A partir de este momento citamos siempre por esta edición y señalamos entre paréntesis las páginas correspondientes, con el fin de agilizar la lectura. 
como «menor». Sus dietarios constituyen un espacio privilegiado de recreación de la memoria individual y colectiva, una atalaya, desde la que observa la realidad cotidiana. El escritor abulense, que ha aprendido en la escuela del periodismo a observar la realidad, despliega con aguda penetración psicológica sus vivencias, muestra la intrahistoria con tono confesional e intimista y da forma a los chispazos de su entendimiento ${ }^{10}$. Al hilo de noticias de la vida social, política o intelectual, de avances científicos y tecnológicos, de la lectura de un libro, de la contemplación de un cuadro, de encuentros con personas, etc., Jiménez Lozano va evocando, con sencillez y fino sentido estético, su mundo de autor. Los dietarios son una joya literaria e intelectual, con la que contribuye a la vitalidad del género y se suma a la tradición literaria de quienes le han precedido y, como él, han sido testigos críticos y privilegiados de su tiempo, que han enriquecido con su mirada lúcida nuestra cosmovisión del mundo. Constituyen una fuente imprescindible para comprender su vida -ofrecen su biografía espiritual ${ }^{11}-$, y son un excelente instrumento para la interpretación hermenéutica de su obra literaria, al presentar las claves nucleares de su proceso creativo -diseminadas en su producción periodística, ensayística, narrativa, etc.- y los adentros del alma del autor; en ellos está inscrita su obra literaria, pues es un texto que «la recorre en su totalidad y que permite acceder al lugar mismo de donde brota» ${ }^{12}$.

Estos cuadernos de notas son fruto del ejercicio de una inteligencia libre, se despliega sin coerciones de ninguna clase y sobresale por la independencia y libertad de su palabra; su escritura permanece en actitud dialéctica respecto a la doxa imperante y crítica con las injusticias y males que aquejan a la sociedad, cuando esta olvida el destino trascendente y prescinde de la dignidad humana. Consciente de que la escritura se inscribe en una historia y cultura determinadas, en una familia espiritual, el escritor no aspira, como ha afirmado, a reformar a los demás, ni la sociedad ni las costumbres, sino a desconfiar de sí mismo, a estar sobre aviso, a despertar las conciencias aletargadas y a alertar de que los seres humanos podemos reflejar la gloria, pero también la barbarie y la brutalidad ${ }^{13}$.

\section{Los tres cuadernos rojos: los demonios del hombre}

El llevar un diario, es decir, la puesta en orden de acontecimientos y pensamientos que afluyen, forma parte de la tarea que se ha asignado el escritor. Es también un consuelo solitario del que siente necesidad. En un

\footnotetext{
${ }^{10}$ Véase M. Merino Bobillo (2011).

${ }^{11}$ A. Medina-Bocos (2003), p. 180.

12 J. R. González (2003), p. 18.

13 J. Jiménez Lozano (2004), p. 57.
} 
momento en que el técnico dirige el Estado y lo modela según su idea, no solamente están amenazadas de supresión las digresiones artísticas y metafísicas, sino también la simple alegría de vivir. Ya ha quedado sobrepasado el tiempo en que resonaba el grito de «la propiedad es un robo». Ahora se considera como un lujo ese carácter propio del individuo que Heráclito llamaba el demonio del hombre. Nuestra lucha por defenderlo y nuestra voluntad de conservarlo es uno de los temas más grandes y más trágicos de nuestro tiempo.

Ernst Jünger

Estas palabras del filósofo, historiador y escritor de diarios alemán, que se presentan como pórtico de Los tres cuadernos rojos, ofrecen las claves interpretativas para nuestro estudio.

Este dietario abarca un período de diez años cronológicos, comprendidos entre 1973 y 1983, aunque no figuran las anotaciones correspondientes a 1978; su título no cabe atribuirlo a cuestiones ideológicas, sino únicamente a la impregnación cromática de los cuadernos en los que fue tomando apuntes. Los tres cuadernos rojos está configurado por entradas breves, que aparecen sin dataciones concretas, salvo las fijadas por los años (esporádicamente las relativas a cinco o seis días del calendario). La razón de este modo de proceder reside en su concepción de que la escritura que trata sobre asuntos humanos no precisa ser fechada, pues el hombre permanece siempre idéntico a sí mismo ${ }^{14}$.

En su nota preliminar, titulada «Ofrecimiento», Jiménez Lozano afirma que decidió relegar «las notas muy personales o los apuntes demasiado esquemáticos e incoherentes o difíciles de entender sin una larga reflexión» (7). ¿Qué finalidades persigue el escritor con sus anotaciones? Están anunciadas: poner en orden sus pensamientos, resistir a las uniformidades que los poderes establecidos pretenden imponer, proporcionar un espacio propicio para la reflexión, un refugio donde se huye de la banalidad y los oropeles del mundo y «ofrecer algún tipo de compañía, conversación o disponibilidad; ese estar ahí, a mano» para acompañar a quien lo necesite (7). La mayoría de las anotaciones contienen, en una simbiosis entre creación literaria y ensayo, reflexiones sobre la condición humana, como las de Herman Broch, Franz Kafka o Robert Musil, etc. El hilo conductor viene marcado por la experiencia interior del escritor; siendo diversos los acontecimientos históricos, sociales, políticos y diversas las historias que le han contado, no es el periodista quien cubre la información, sino el hombre que, paradójicamente, pasa con agilidad de la referencia externa a la dimensión interior de la conciencia.

¿Cuáles son las líneas argumentales de sus anotaciones? Podemos circunscribirlas a los ejes intelectuales que han presididido su quehacer periodístico desde 1956, en las columnas «Ciudad de Dios» y «Mano Abierta», que publicaba en

14 J. Jiménez Lozano (2004), p. 57. 
El Norte de Castilla, en el suplemento dominical «Las Artes y las Letras», y en el suplemento «El caballo de Troya» ${ }^{15}$ : la defensa de la libertad y la búsqueda de la verdad, la dimensión religiosa de la condición humana, el problema religioso que entraña el ejercicio de la libertad de conciencia, la denuncia de los totalitarismos de cualquier signo, la defensa de los débiles y las víctimas, etc. Los tres cuadernos rojos constituyen un documental excepcional sobre la historia intelectual, política y social del mundo contemporáneo; reflejan la lucidez del escritor y su lucha contra la barbarie y contra la primacía otorgada al desarrollo científico, cuando va en detrimento de los seres humanos convertidos en víctimas experimentales, como muestra la teoría pavloviana de los reflejos «levantada sobre sangre y con sangre» (136).

\subsection{Complicidades lectoras y polifonías textuales}

Sin miedo a que los libros le trastornen la cabeza, son muchas las obras, literarias o no, que desfilan a lo largo de Los tres cuadernos rojos, como las lecturas de Dostoievski y de San Juan de la Cruz, realizadas al arrimo de unos muros de adobe de una destartalada casucha de campo, donde había fallecido una de esas pobres gentes, humilladas y ofendidas, que habitan su narrativa: «Y de los míos, de las historias que tengo que contar de 'pobres gentes', de esas santidades irrisorias, de estos ignotos místicos que han apurado hasta el final todo el acíbar de la existencia [...]» (28); la profecía de Jonás (32); el Tractatus theologicus-polithicus y Ethica, de Spinoza (42); Les Thibault, de Roger Martin du Gard (55); el documento «Declaración acerca de ciertas cuestiones de ética sexual», de la Sagrada Congregación para la Doctrina de la Fe de 1975 (58-59); El otro proceso de Kafka, de Canetti (61); El espectador, de Ortega (100); La montaña mágica, de Mann (73); la Geografía, de Estrabón (73); Bajo el sol de Satán. Historia de Mouchette, de Bernanos (79); Billy Budd, de Melville (79); Los hermanos Karamazov, de Dostoievski (81); el cuento «El procurador de Judea», de Anatole France; los paisajes nórdicos del danés Steen Stensen Blicher y del dramaturgo luterano Kaj Munj (83); Macbeth, de Shakespeare (86); La Revolución francesa: una historia, de Thomas Carlyle; la Divina Comedia, de Dante (86); El idiota de la familia, de Sartre (147); Temor y temblor, de Kierkegaard (116); Une jeune homme à la recherche de l'amour, de Isaac Bashevis Singer; El mundo de ayer, de Zweig (131); La terre est si belle, de J. Green (146); Els secrets de Sa Bardissa, de Jaume Aymar y Ragolta (146-147); Montaillou, una aldea occitana, de 1294 a 1324, de Le Roy Ladurie (150), entre otras.

Conducido por el anhelo de aprender qué es el hombre y qué misterios e infiernos lo sacuden interiormente, Jiménez Lozano acude a la lectura de obras que lo hieren en lo vivo, pues no ocultan la presencia del mal y se preguntan por el

\footnotetext{
${ }^{15}$ Puede ampliarse esta información con el trabajo de M. Merino Bobillo (2010).
} 
silencio de Dios frente a la cruz. No es otra la esencia de la escritura: «porque la vida hiede y la belleza debe hacerse presente, sin mostrarla nunca. De otro modo se convertiría en bibelot, sensaciones y refinamiento, como en Proust: pura sacarina. Aunque la sacarina sea sublime» (79). Así, junto a las obras de Simone Weil (123) o Bernard Shaw y Evelyn Waugh (123), no faltan las lecturas poéticas de John Keats (32), Giuseppe Ungaretti (42), Nikos Kazantzakis (89), o Pablo Neruda (16); la Antología lírica Con el carbón del sol, de Juan Ramón Jiménez (92); el poema If I shouldn't be alive, de Emily Dickinson; el poema dramático Una noche con Hamlet, de Vladimir Holan (100), como manifiesta el poema «La resurrección», que copia en su dietario $(148)^{16}$; Solejar de las aves, del sacerdote abulense y amigo Jacinto Herrero Esteban (104); Noche oscura del alma, de San Juan de la Cruz (62); la edición bilingüe de la antología poética de Gerard Manley Hopkins, que publicó Manuel Linares Megías en 1978, que «debería ser un acontecimiento espiritual y agitar algo las muertas o alejandrinas aguas de nuestra cultura» (83).

Numerosas anotaciones muestran la impronta de las lecturas de obras de carácter autobiográfico como el epistolario de Flaubert (195); Diario del 71 y de 72, de Eugenio Montale, $(63 ; 128)$; La terre est si belle, diarios que Julien Green escribió entre 1976 y 1978 (146); Selected Letters of John Keats, publicadas en 1951 con introducción del estadounidense Lionel Trilling (146); las memorias de Nadejda Mandelstam (106); Journal de captivité (1942-1943), del filósofo Jean Guitton (141), etc.

Algunas lecturas le ofrecen al escritor la posibilidad glosar de manera oportuna las cuestiones intelectuales que lo inquietan: la invectiva contra los efectos perniciosos de la lujuria, en Reprobación del amor mundano o Arcipreste de Talavera (12); las tesis socialistas de un poeta proletario en La luz del mundo, del Nobel islandés Häldor Laxness (17); la descripción del Día del Juicio, que penetra en la urdimbre misteriosa que encierra la vida de todo hombre en el himno latino del siglo XIII Dies irae (18); la conciencia agudísima del apocalipsis de la civilización ante el avance tecnológico, que se halla en la obra de W. H. Auden (16) y de Zweig (17); la crítica a algunas conductas de la clerecía, como la intromisión en asuntos temporales, presente en las obras de Stendhal (22); el temor a la destrucción del mundo por la guerra atómica, que hace pasar por enajenados y locos a quienes toman conciencia del espanto en Los Físicos, del escritor suizo Friedrich Dürrenmatt (58); la atmósfera de pobreza y sordidez espiritual, en que vivían Dostoievski y su segunda esposa Anna Dostoievskaia, un «humus» que ilumina la belleza perturbadora que preside El idiota y que ella desgrana de manera descarnada en sus diarios íntimos, que fueron publicados en la URSS en 1973 y

\footnotetext{
16 Jiménez Lozano anota en 1982 el poema «La resurrección», traducido por Clara Janés; debió tomarlo del poemario Avanzando, de Vladimir Holan (Madrid, Editora Nacional, 1981).
} 
traducidos al francés como Journal. Les carnets intimes de la jeune femme de Dostoievski en 1978, año de la anotación, aunque no consta (76); el pensamiento del biólogo y filósofo francés Jean Rostand (105); la desnudez del alma en El presidente (1958), de Georges Simenon (119); la condena de la «ley de la moda» que los medios de comunicación imponen, una antítesis del pluralismo ideológico que debe reinar en la sociedad, una tesis que comparte con Jorge Santayana (122); la finura de espíritu de John Henry Newman, que tanto le recuerda la obra de Tertuliano, Séneca o Montaigne $(72,95)$, etc. Como vamos viendo, Jiménez Lozano es, como su admirado Zweig, hombre de amplias y vastas lecturas. Con una conciencia lúcida de la realidad y de los valores verdaderos, que se distinguen de aquellos que azuzan a las masas buscando halagarlas y corromperlas, como a las víctimas de sus narraciones (132), critica las manifestaciones que reviste la mediocridad espiritual e intelectual, lanza sus diatribas contra las utilizaciones políticas e ideológicas de las vidas de los santos, como muestra a través del banquete que las autoridades ofrecieron en Fontiveros con motivo de la inauguración de un monumento a San Juan de la Cruz (13); etc.

\subsection{Memoria passionis}

El escritor abulense pretende recuperar la memoria de la historia y dar acogida a la voz de los sujetos de desgracia; desde siempre le han apasionado e intrigado las vidas de los pobres hombres, «que el polvo parece haber devorado pero gritan dentro de nosotros mismos». El yo narrador ha sido testigo oral de las narraciones de la guerra civil y de la represión sufrida; Jiménez Lozano custodia con una inicial la identidad de las personas que las protagonizaron y con quienes ha dialogado como interlocutor privilegiado. Este anonimato -rasgo configurador de los siguientes dietarios- sobresale como muestra inequívoca del exquisito respeto a la privacidad individual: L, con quien discute sobre procesos inquisitoriales (25); el profesor D. K, con quien disputa sobre las tesis de Américo Castro (38); monseñor $\mathrm{X}$, interesado en involucrar asuntos religiosos y clericales con cuestiones políticas de Presidencia del Gobierno (39); X, un viejo arcipreste que había vivido obsesionado con la muerte y la sepultura civil que había recibido un médico de pueblo (42); R.C., con quien charla del modernismo (52); X, campesino de los alrededores de San Miguel de Escalada, con quien habla de las atrocidades de la guerra civil (71); el matrimonio B y T.M., con quien trata sobre literatura y teología (102), etc.

Generalmente son historias atroces de seres que un día conoció y cuyo rostro sigue viendo con nitidez, que parecen «ángeles terribles» y le evocan el sufrimiento de los personajes de Dostoievski, Faulkner, Gorki, Bernanos (122), o al mismísimo Juan de la Cruz; seres que, como aprendió de Simone Weil, «sostienen el mundo, la historia y el pensamiento» (122). Nacen las historias con el deseo de «preservar de la muerte o la ruina a alguien», de ofrecer siquiera «una brizna de belleza», como la del epitafio de una inscripción funeraria que encuentra en Santa María de Arbás: 
«Luis Menénez Pidal Álvarez, Arquitecto. ¡Oh Dios, salva su alma de la perdición cmo él salvó esta iglesita de la ruina! 16-VII-1893 - 28-XI-1975» (89). Con otras historias Jiménez Lozano se muestra combativo contra quienes han pretendido arrancar del corazón humano la esperanza y mostrar el triunfo de mal con el uso arbitrario del poder, critica las reformas educativas encaminadas a ahormarlo a los facta de la historia y censura el dominio del mundo a través del dinero y el poder, como manifestación del fracaso de la encarnación del Verbo (21).

Algunas anotaciones de Los tres cuadernos rojos contienen historias reales, que hirieron el alma del escritor y han sido el germen de futuros cuentos; una anotación de 1973 reconstruye la muerte de un cura acaecida en los años cincuenta, que está en la base de «El escopetazo», en El santo de mayo ${ }^{17}$, según cuenta en Los cementerios civiles; o la historia, contada por un forense, sobre una muchacha de dieciocho años que se quitó la vida, tras dejar en la mesita de noche una carta en la que explica los motivos de su suicidio, motivo que centra futuras narraciones como «La carta» y «El sobre azul», en El cogedor de acianos; la historia de un personaje dostokievskiano $\mathrm{X}$, una muchacha campesina con rostro desfigurado, sin apenas nariz, que busca trabajo sin lograrlo (38); la de una mujer que tuvo doce hijos, de los cuales sobrevivieron aquellos cuyo nacimiento coincidió con el de los hijos de una vecina o amiga, que los amamantó (82), etc.

Son muchas las historias que se cuentan y suscitan temas controvertidos: la participación de Juan Sánchez, el abuelo de Santa Teresa -un mercader judío convertido al cristianismo, que tenía en Toledo un negocio floreciente-, en la procesión de penitenciados que decretó la Inquisición en 1486, tras renegar de su religión y confesar el delito el 22 de junio de 1485 (9); la visita de un ilustre escritor a un anónimo gobernador de Cádiz que había ordenado la detención de un joven por comportamiento anticívico, historia a través de la cual denuncia los privilegios sociales y políticos que gozaron algunos en la década de los cuarenta (10-11); los primeros contactos con las letras en algunas escuelas rurales a través de las bulas de la Cruzada, que mitigaba ayunos y concedía indulgencias con la aportación económica de los fieles (12); la propuesta de Jonhattan Swift en un breve tratado, cuyo título no se explicita y que debió ser «A modest proposal», de bosquejar unas medidas descabelladas para eliminar a los pobres de la sociedad irlandesa (20); los Autos de fe y la quema de herejes a las que asistían damas de otro tiempo (20); o la endura -un rito de purificación (vida de austeridad, oración, riguroso trabajo y ayuno en las grutas de Ussat-Ornolac), practicado por los cátaros, que fueron declarados herejes-, que le evoca la vida de dos tuberculosos que eligen morir entre colillas, quizá al comprobar que no eran aptos para la lucha por la vida (23). Como podemos constatar a lo largo de las anotaciones de Los tres cuadernos rojos y de las historias que en ellas se narran, aparecen diseminados algunos temas que vuelca

${ }^{17}$ J. Jiménez Lozano (1976), p. 19. 
Michel de Certeau en L'invention du quotidien (1974) y La culture au pluriel (1974): la construcción de las estrategias ideológicas y políticas del poder en los espacios urbanos, al margen de los intereses de las vidas individuales; las estrategias de dominio que se despliegan desde los medios de comunicación, espacios de interacción mediática y cultural, que mediante tácticas guían de manera conductista y homogeneizada a las audiencias.

Aparecen referencias a los últimos años de la dictadura y a las ilusiones forjadas ante el régimen democrático por un pueblo, que había sido educado secularmente en la veneración del autoritarismo (26); las inclusas o casas de beneficiencia, que daban acogida a niños expósitos abandonados por sus padres (27-28); los actos religiosos de hipocresía cometidos ante la presión social o política (32); la clandestinidad de la mujer, condenada a pasar su vida en cubículos de orden diverso (gineceo, harem, alcoba, etc.) (41); la actitud vital e intelectual de José María Sagarra, creyente temeroso de ser visto por la Iglesia durante la posguerra española, que evita trasladar a su obra literaria (La corona d'espines o La herida luminosa) su drama interior y existencial, adoptando una postura semejante a la de Bergson, quien no quiso bautizarse mientras los judíos eran perseguidos en la Alemania nazi y en la Francia de Vicky (60); la censura de los años cuarenta, cuando se tachaba el término «axila» en un artículo de Víctor de la Serna (61); el rechazo de las críticas a Carrillo o de las culpas atribuidas al Concilio sobre la pérdida de la Iglesia (68); las luchas político-religiosas de monseñor Mateo Múgica, obispo de Vitoria, a quien Franco persiguió y desterró por su vasquismo intransigente (101); el golpe de Estado de Tejero en el Congreso de los Diputados el 23 de febrero de 1981 (107); la falta de conciencia ética civil en España, como se deduce del comportamiento de la Administración ante la denominada "neumonía atípica", causada por el aceite de colza desnaturalizado, que tantas víctimas se cobró en las capas más desvalidas de la sociedad (119), etc.

\section{3. Controversias teológicas. Transversalidad del hecho religioso}

Teniendo en cuenta que una de las manifestaciones del espíritu humano es la apertura a la temporalidad, las realidades temporales y la trascendencia son dos de los núcleos que vertebran las nociones ontológico-existenciales del pensamiento del escritor. Jiménez Lozano permanece atento a la situación intelectual y espiritual en que se encuentra el mundo occidental y algo más distanciado de la realidad cotidiana, que impera en los dietarios posteriores. Mientras percibe las lagunas, carencias y logros del hombre contemporáneo, dialoga con los intelectuales de todo tiempo y se plantea las inquietudes que lo acechan (la interpretación de la historia, la existencia del mal, la dimensión religiosa, etc.).

Su pensamiento, esencialmente dialógico, se nutre del ejercicio de la razón y de las fuentes de la revelación, con las cuales interioriza experiencias históricas e intelectuales. En Los tres cuadernos rojos abundan las reflexiones teológicas e históricas, que muestran interés por la dimensión espiritual del hombre de su tiempo, 
una temática que recorre transversalmente el dietario y se convierte en un rasgo distintivo del mismo, presente también en su labor periodística ${ }^{18}$. ¿A qué se puede atribuir esta presencia de la dimensión religiosa? La razón la podemos encontrar en la fecha de redacción de estos apuntes. Las anotaciones comienzan en 1973, unos años después de la culminación del Concilio Vaticano II (1962-1965); se sitúan en el contexto del proceso de su recepción en la Iglesia, cuando aún no había tomado forma la respuesta a la cuestión teológica relativa a cuáles habían de ser las actuaciones del cristiano en la política y en la sociedad. En 1963 el joven periodista había sido enviado como corresponsal a Roma por El Norte de Castilla -dos años antes de su incorporación definitiva como redactor al órgano de prensa que dirigía Miguel Delibes- y por la revista Destino, donde publicó sus artículos y crónicas en la sección «Cartas de un cristiano impaciente»; en algunas obras posteriores al fin del Concilio ya había reflexionado sobre el espíritu conciliar y sobre la libertad religiosa como en su ensayo Meditación española sobre la libertad religiosa (Destino, 1966), que tendría su continuación en «El aporte del profesor Américo Castro a la interpretación del sentimiento religioso español» ${ }^{19}$. Este es el eje de sus dos primeras novelas: Historia de un otoño (Destino, 1971), sobre la resistencia de las monjas de Port-Royal des Champs al poder de Luis XIV y del papado, «el primer acto de una conciencia civil en la modernidad histórica» ${ }^{20}$; y El sambenito (Destino, 1972), una recreación del proceso inquisitorial de Pablo de Olavide.

El escritor abulense reprocha la actitud de quienes pretenden bautizar a la sociedad sin dejar margen al pluralismo ideológico, contribuyendo a que quienes piensan diferente sean excluidos, marginados o considerados herejes; recrimina los ataques que a lo largo de la historia ha recibido la libertad político-social del individuo; defiende el ejercicio de la libertad individual frente a los abusos del poder y la subordinación del poder al derecho; y censura las actitudes despóticas y fanáticas adoptadas por quienes, en nombre de las ideologías, se apropian de la verdad y las revisten de argumentaciones con las que imponen sus credos, y por quienes consideran que los seres humanos no podrán convivir en una sociedad justa y pacífica, si ellos no les imponen sus valores supremos. Adelantándose a la doctrina proclamada en Centessimus Annus (1991), el inconformista intelectual abulense sostiene la primacía política de la libertad de la persona sobre los aparentes derechos de la verdad y manifiesta reiteradamente su convicción de que los derechos solo pueden poseerlos las personas, pues en términos jurídicos y políticos ni el error ni la verdad los poseen; se enfrenta a cuantos en el seno de la sociedad civil o eclesiástica sitúan en el Estado la imagen visible del Dios invisible; y se opone a la sacramentalización de los poderes terrenos al servicio de la

\footnotetext{
${ }^{18}$ Véase M. Merino Bobillo (2011).

${ }^{19}$ Véase J. Jiménez Lozano (1971b).

${ }^{20}$ J. Jiménez Lozano y G. Galparsoro (1998), p. 24.
} 
salvación y a la pretensión de crear una civilización virtuosa bajo de la dirección de la Iglesia ${ }^{21}$.

Percatándose de la complejidad de las realidades humanas, se acerca a la realidad histórica y, con la flexibilidad propia de quien no asume posturas ni tonos dogmáticos, muestra resistencia pacífica contra los cercos que imponen los totalitarismos políticos e ideológicos e intenta construir una sociedad misericorde y humana en nombre de quienes están condenados al silencio; no divide el mundo en buenos y malos; con pluma afilada censura toda forma de violencia, también cuando se ejerce en nombre de Dios o de la Iglesia, como camino para asegurar la salvación, como las muertes decretadas a los herejes por la Inquisición.

Defensor de la independencia del hombre frente al estado, el escritor abulense se muestra receloso ante la desfiguración de las relaciones entre la libertad y la verdad que entrañan el fundamentalismo y el totalitarismo moderno, cuya raíz, como proclama la Centessimus Annus, reside «en la negación de la dignidad trascendente de la persona humana, imagen visible de Dios invisible y, precisamente por esto, sujeto natural de derechos que nadie puede violar: ni el individuo, el grupo, la clase social, ni la nación ni el Estado» (núm. 44). Proclama la dignidad de todo hombre, especialmente, de los pobres y desposeídos de patria y de dignidad, que se convierten en un imperativo moral para toda la humanidad, pues todo hombre es un absoluto, nunca un medio que pueda ser instrumentalizado. Y lamenta que haya penetrado en la Iglesia el sentimiento de secta, del que hablara el sacerdote francés Pierre Dubois; así lo refleja, tras escuchar, durante el rezo de vísperas en la Trapa de Arévalo, la petición por la situación política que se vivía en Polonia y España, mientras se olvidaba a las personas que estaban siendo brutalmente asesinadas en El Salvador o Guatemala (127).

Muchas de sus lecturas derivan de su deseo de acompañar "en el mismo camino, en la misma nave, bajo la misma noche» (84) al hombre de su tiempo, sea cual sea su credo religioso o político. Es esta una de las misiones que atribuye al creyente de todos los tiempos, como se deduce de las reflexiones efectuadas en 1979 tras la lectura del pensamiento del filósofo y teólogo luterano Paul Tillich, quien, comprometido con el socialismo religioso, sostuvo que la riqueza del credo cristiano reside en su adecuación al horizonte de significación del hombre de hoy (84).

Para Jiménez Lozano el cristianismo es una religión de encarnación y asunción de las realidades humanas y una luz que no puede violentar las inteligencias humanas ni infringir sus derechos, ni ser arrojada contra ellas. Subraya cómo las pasiones ideológico-religiosas se han alimentado de leyendas que, propaladas sin verificación alguna, terminan por desollar a sus víctimas. Así, en una anotación de

${ }^{21}$ Puede ampliarse información con M. Merino Bobillo (2010) y S. Moreno González, (2010). 
1979 narra la historia que le cuenta un protestante sobre la visita que hizo un 24 de agosto en la cárcel de Toro a un preso, leído y formado, que le recordó las guerras de religión que enfrentaron a católicos y calvinistas franceses y el asesinato en París de franceses calvinistas por mandato del rey Carlos IX de Francia ese mismo día del año 1572, un suceso que le lleva a recordar la imagen que de dicha cárcel extrajo George Borrow, tras viajar por España entre 1836 y 1840 repartiendo biblias protestantes: «La fe es, desde luego, una aventura vital como el amor, pero no un juego al pitajuelo o a las tres en raya de Derecho Canónico, o al azar de fronteras y tapiales decididos por los hombres» (87).

En Los tres cuadernos rojos ocupan un papel destacado las alusiones a los procesos inquisitoriales que sufrieron los hebraístas salmantinos, como Martín Martínez de Cantalapiedra, Luis de León, o Gaspar de Grajal (51), y al terror (territio) tan brutal que despertaba la exhibición de los instrumentos de la tortura. que suplía a la tortura misma (34), etc.; no faltan tampoco las analogías entre las conversaciones mantenidas a puerta cerrada o en el cuarto de dentro durante los años del Santo Oficio y durante la posguerra española (34-35). La investigación realizada sobre herejes locales recibe tratamiento a lo largo de algunas anotaciones, en las que alude a los silencios administrativos de las personas entrevistadas, celosas de «guardar memorias que no convienen» (53); las historias relativas a la persecución emprendida contra los clérigos en la zona republicana y las parodias sacramentales cometidas -algunas de las cuales están en La salamandra (Destino, 1973), las cuales le recuerdan algunas escenas del barroco con sus odios y revanchas-; o las violaciones perpetradas en un convento de monjas, que había contado con fruición uno de quienes lo perpetraron (95), etc.

Es especialmente relevante una extensa anotación, que consagra a la relectura que hizo en 1973 de algunas biografías, cartas y memorias de los protagonistas del modernismo teológico, un fenómeno que, a pesar de tener en San Manuel Bueno unamuniano uno de sus frutos, tuvo intelectualmente escaso impacto en el ámbito hispánico; alude ahí a la crisis existencial y religiosa de Alfred Loisy, Albert Houtin, el exjesuita inglés George Tyrrell, Joseph Turmell, Marcel Herbert, el barón Von Hügel, Miss Maude Petre, Maurice Blondel, Ernesto Bounaiutti y Félix Klein. Son muchas las obras referenciadas: La lumiére de la maison, de Jean Nesmy; Le Démon de Midi, de Paul Borges; Il Sant, de Antonio Fogazzaro; Augustin ou Le maitre est là, de Joseph Malègue; Robert Elsmere, de Mrs. Humphry Ward; y Jean Barois, de Roger Martin du Gard, que le provocó un "trastorno espiritual" (30); Les dermiéres semaines d'Alfred Loisy, de Edmond Coste; El evangelio y la iglesia, de Alfred Loisy, que Jiménez Fraud tradujo el mismo año en que comenzó a dirigir la Residencia de Estudiantes, como reacción católica crítica frente a la visión protestante del cristianismo que Aldof von Harnack ofrecía en La esencia del cristianismo (53), etc.

Acoge las reflexiones de intelectuales controvertidos en la historia de la Iglesia, como las del téologo austriaco Adolf Holl, quien en Jesús en mauvaise compagnie, 
versión traducida de Jesus in schlechter Gesellschaft (1971), se aproximó a la figura de Cristo desde perspectiva sociológica (112); o el del jesuita francés Teilhard de Chardin (112), a quien venía leyendo desde su juventud como muestra su artículo «La fiesta de los 'guardadores del pan'. Diálogo de un santo y dos filósofos» ${ }^{22}$ (publicado en 1958 en El Norte de Castilla), a quien considera "gigante del pensamiento en nuestro tiempo, y quizá el primer clérigo de la historia que, de verdad, confía en la razón humana» (112-113). Defiende la necesidad de liberarse de los sambenitos que pesan sobre personas y familias enteras (66); y critica los símbolos con que se ha adornado el poder a lo largo de la historia, rememorando la escena del cardenal Richelieu, afectado de fístula anal y sentado rodeado de cortesanos para defecar, o del ministro de Franco, que denuncia un sabotaje tras el apagón que provocó el parón del ascensor en que subía el general en la clínica de la Paz (77).

Asimismo, Jiménez Lozano muestra a través de sus anotaciones y de sus historias la sabiduría profunda que encierran los relatos bíblicos y los místicos, pues solo ellos se han atrevido a expresar, "como la esposa del Cantar de los Cantares, y eso les ha costado sangre» (115).

\subsection{Ante el vértice de la nada o la muerte}

La presencia de la muerte, que atribula al alma ante la instancia del juicio y la presencia del Deus absconditus, es recurrente en las anotaciones. Algunas historias suspenden al lector ante el vértice de la nada. Con frecuencia la muerte - vista como un acontecimiento capaz de paralizar la historia, aunque sea hipócritamente, en todas las civilizaciones (29)- se tiñe del respeto sacral, visible en la lumbre que no se encendía ni el Jueves ni Viernes Santo «porque Dios había muerto» (76). Sorprende el miedo con que la afrontan algunos prelados (27) o un aristócrata aterrorizado, a quien la muerte terrible lo sorprende abrazado de tal manera a la condesa que «para separarlos hubo que descoyuntar los brazos del esposo» (89); este miedo, que el escritor deduce de la lectura de Devotions, de John Donne (77), es el temor al innombrable «cajón» de un modesto campesino, que recuerda que, siendo niño, a los muertos les ataban los pies y las manos y los colocaban encima de una colcha de colores (91).

Es profunda la huella que deja la muerte en objetos (muebles, cortinajes, coches de caballos, colecciones de mariposas disecadas, etc.); no faltan en este sentido algunos recuerdos de infancia que hirieron su alma, como la costumbre materna de guardar la cinta blanca de seda que había estado en el ataúd de una amiga que falleció en plena juventud; o las alcobas de algunas casas burguesas que permanecían cerradas porque alguien había muerto en terribles circunstancias (4748 ), etc. Refleja comportamientos ejemplares, como la ternura con que unos padres

22 J. Jiménez Lozano (1958). 
con el corazón desgarrado custodian el cadáver del hijo recién nacido en la portería de la casa en la que trabajan (43); el arrepentimiento del párroco de un pueblo castellano que, tras haber estado comprometido con la represión política de la guerra civil, en el momento de la muerte recorre el pueblo de rodillas y con los brazos en cruz (44); o la terrible muerte de la priora de las carmelitas de Compiègne, guillotinada durante la Revolución Francesa, narrada en Diálogos de Carmelitas, de Bernanos (37); etc.

Jiménez Lozano critica los maquillajes con que los hermeneutas han intentado disfrazar el encuentro con la muerte o el dolor y revestir la soledad y dureza, que sufrieron Teresita de Liseux o Juan de la Cruz en sus conventos respectivos (37). Toma registro de algunos óbitos, como el de Nadejada Mandelstam el 5 de enero de 1981 -se hace eco por el diario Le Monde-, cuyo libro Contre tout espoir, releído hasta siete u ocho veces, ha herido profundamente el alma al escritor (106); o el 7 de enero de ese mismo año de Giuseppe Lanza del Vasto, autor de Peregrinación a las fuentes, que leyó con voracidad siendo estudiante (106). Tampoco falta el registro de algunas tentativas de suicidio, como la de $\mathrm{X}$, sacerdote de gran sensibilidad (pintor, músico, poeta) que, tras vivir varios años en diversos países de Sudamérica, volvió con la fe destrozada tras contemplar las injusticias cometidas contra las gentes (40); los de Stefan Zweig y su mujer, incapaces de soportar la barbarie, el desmoronamiento de la cultura y el desprecio de la inteligencia (79); etc.

Bastantes anotaciones de Los tres cuadernos rojos giran en torno a la investigación que el escritor abulense realizó para la escritura de Los cementerios civiles y la heterodoxia española (1978); en ellas alude a la lucha decimonónica, y también de comienzos de siglo XX, existente en torno a esta realidad, reconocida por el Derecho Canónico (41). El estudio de la inscripción, que figura en el enterramiento civil de un registrador de la Propiedad, le lleva a entrevistarse con algunas personas, que guardan memoria de los rastros que formarán parte del sedimento cultural de un mundo ya desaparecido (49-50); el mendigo que fue enterrado en un cementerio civil de Andorra, por ser desconocido, al parecer, judío errante (53); el pobrecillo, que durante la posguerra española se ganaba la vida con las propinas que le daban como guardacoches, a quien las autoridades habían puesto un brazalete con la leyenda «anormal» para evitarle problemas con la policía (58); la lápida del cementerio civil de un pueblo que corresponde a la mujer de un agrimensor no creyente, a quien ella siguió en su increencia, abandonando el catolicismo (87); o la soledad que rodea la muerte de un escritor español, experto en arte, cuyas cenizas inhumadas fueron depositadas en el cementerio civil (62), etc.

\subsection{Apertura dialógica a la temporalidad}

El escritor, heredero del espíritu crítico de la modernidad en ámbitos diversos (filosófico, social, religioso, político), reacciona contra las deformaciones del racionalismo y la reducción de lo humano a esquemas racionales (150). Arrojando por la borda la astenia ética y despojándose de la moral anoréxica y debilitada, 
censura el envilecimiento, que se deriva de negarle al hombre la capacidad de penetrar la realidad y de negar los principios morales; defiende con ardor la demanda pública de la conciencia; y acusa a los regímenes políticos e ideologías que sojuzgan la conciencia y hunden a los hombres en la indolencia. Defensor de la libertad de expresión y de pensamiento, de los derechos de la persona para manifestar sus credos ideológicos, políticos y religiosos, muestra que, a pesar de los progresos alcanzados con la adquisición del saber y de las libertades a partir de la Revolución Francesa, se dan muchas situaciones de connivencia con la falta de derechos humanos y con el aniquilamiento de la libertad de los pueblos y de las libertades individuales, como expresa en 1982:

Humanistas de Europa entera, atiborrados de griego y latín, asistían a sesiones de tortura, lores educados en Oxford o Cambridge encontraron natural la esclavitud $\mathrm{y}$, desde luego, no se consideraban de la misma especie que las «clases inferiores», y profesores y aristócratas alemanes aplaudieron lo que sucedía en Auchswitz (sic) o tomaron parte activa en aquel horror. (136)

Jiménez Lozano, también él hombre de frontera y de inquietud como él consideró a D. Lazaro Bardón (48), perplejo ante el aislamiento oficial y rígido de la España de la segunda mitad del siglo XX, ofrece sin paliativos lingüísticos una visión crítica de la cultura española, una «aldea cultural» (112) que, aislada de la influencia de elementos foráneos, se encuentra inmersa en el anquilosamiento intelectual y espiritual, del que difícilmente puede escapar.

En diálogo constante con la cultura occidental, sus apuntes diseccionan con brillantez la sociedad de su tiempo, sin menospreciar la mirada histórica. No faltan las referencias a asuntos políticos, como la censura de los espectáculos durante la presidencia de Arias Navarro (39); una visión crítica del enfoque democristiano de Cuadernos para el Diálogo, revista promovida por Joaquín Ruiz-Giménez entre 1963 y 1978, que fue un referente de la cultura progresista (40); la muerte de Franco (53); la constitución de la Junta de Ampliación de Estudios mediante Real Decreto firmado por Alfonso XIII en 1907, tras seguir el consejo otorgado por el conde de Romanones a don José Castillejo de dejar de lado la aprobación por vía parlamentaria (67); los miedos suscitados por la legalización del Partido Comunista en España y por la libertad de culto (69); las cintas magnetofónicas de propaganda política de la derecha que, a pesar de la prohibición episcopal, se introdujeron en los conventos de clausura en nombre del catolicismo, con el fin de detener el avance del marxismo (70); la muerte de Pablo VI, a quien describe como un hombre torturado espiritualmente (71); el fallecimiento del intelectual Ignacio Silone (cuya obra literaria admira), uno de los fundadores del Partido Comunista italiano, que fue enterrado bajo una piedra sin inscripción, entre unos cipreses y pinos en las proximidades del ábside de San Berardo en Pescina (71), que dejó a su partido en herencia dos mesas, unas sillas y unos ficheros de trabajo, según cuenta el Jefe del 
Partido Marco Panella (108); la censura que sufrió Alejandro Díez Blanco, catedrático de Filosofía y profesor suyo, tildado de kantiano por el Ministerio de Cultura (100), que fue semejante a la que sufrió el periodista y sociólogo Santiago Valentí Camps, a quien el Tribunal Supremo en 1909 consideró «kantiano exaltado»; el ametrallamiento de unos jóvenes del Bloque Popular Revolucionario por parte de los cuerpos de seguridad en las escalinatas de la Catedral de San Salvador (habían tomado el templo) el 8 de mayo de 1979 (la anotación no está datada), un hecho que le conduce a denunciar los crímenes que se cometen a plena luz del día y son reclamados orgullosamente por quienes los perpetran (85-86); la amargura de la soledad y del silencio que rodea a Adolfo Suárez, en otros momentos laureado - la anotación es de 1981, año en que abandona la Presidencia del Gobierno- (119), etc.

A través de apuntes mínimos José Jiménez Lozano brinda con concisión prodigiosa una galería de retratos y semblazas en el escenario social e histórico en que vivieron: Max Horkheimer y la escuela de Frankfurt (13); el escritor José Somoza, procurador de las cortes de Ávila, que fue encarcelado por Fernando VII por su liberalismo, quien, ante el miedo a que se le enterrara en el cementerio que el duque de Alba había construido en su coto de conejos, fue sepultado en su hacienda La Pesqueruela (14); las hermanas Brönte, Emily y Charlötte, hijas del pastor de Haworth, «que pasaron su infancia y juventud en el presbiterio desde el que se veía el cementerio parroquial en cuya tierra ellas serían enterradas bien tempranamente» (17); la semblanza de don Antonio Machado a través del dibujo de su habitacioncilla en la pensión de la calle de los Desamparados de Segovia (19); el farmacéutico José Rodríguez Carracito, ateneísta eminente, obsesionado con las promesas de fabricación de la vida humana en un laboratorio (25); la misoginia de Quevedo (41); el anticlericalismo de Ramón J. Sénder (93); el doctor Francisco Suñer y Capdevila, republicano y ateo (94); Kurt Gertein, el espía de Dios -como lo denominó Pierre Joffroy en su homónima biografía con una expresión que tomó del Pastor Rehling (amigo de juventud) y de Kierkegaard: Un espia que al servicio de Dios descubre el crimen de la cristiandad, que es el de llamarse cristiana cuando no lo es-, que combatió desde el interior el régimen nazi (había ingresado en las filas del NSDAP) y elaboró un relato con los horrores de los crímenes perpetrados en los campos de la muerte (136); etc.

Jiménez Lozano se suma a todos los intelectuales (católicos o ateos, clérigos y hombres de letras, representantes de la crítica histórica de las religiones o hermeneutas bíblicos), que han abordado la cuestión de la crisis de fe provocada por el positivismo científico y han crecido en torno a dos hechos cruciales en la historia de las ideas: el liberalismo protestante y el modernismo.

Desde el exilio interior emprende esta ruta intelectual por caminos solitarios o se conduce solitario por caminos trillados, como Kierkegaard, siempre con apertura hacia la trascendencia y con escepticismo respecto a los asuntos sociales y políticos. 


\section{Conclusiones}

Jiménez Lozano imprime un tono personalísimo a Los tres cuadernos rojos, un dietario en el que la escritura brota como un ejercicio de reflexión, que se encuentra a medio camino entre la creación literaria y la anotación ensayística. Desfilan en sus anotaciones, correspondientes al período comprendido entre 1973 y 1983, las vastísimas lecturas, que nutren la savia humanística y filosófica del escritor: Dostoievski, San Juan de la Cruz, Spinoza, Canetti, Flaubert, Julien Green, Guitton, Mandelstam, Simone Weil, Zweig, etc.

Nos encontramos, como hemos ido revisando, ante un cuaderno de notas de cuño literario e intelectual, en el que el escritor abulense aborda con lucidez acontecimientos históricos o cuestiones complejas que requieren una honda labor hermenéutica. Es vastísimo el abanico de temas tratados, que se extienden desde la defensa de la libertad de conciencia, la denuncia de los totalitarismos o la lucha contra todas las manifestaciones de barbarie humana, hasta las consecuencias del positivismo científico, de la posmodernidad o de la intromisión del poder en el espacio de las libertades humanas, etc. Con gran finura de espíritu y desde una actitud dialógica con la cultura, la filosofía y el pensamiento religioso, Jiménez Lozano toma registro notarial de los acontecimientos, recupera la memoria passionis del ser humano y explora las contradicciones del hombre de su tiempo.

Estos apuntes diarísticos aúnan la escritura simplicísima con el elevado lirismo y profundidad de pensamiento y buscan la forma esencial del ser, que pretendiera Bernardo de Claraval, quien anhela como el Rey Midas transformar «en belleza cuanto toca y dice» (143), a la espera de un lector que en silencio interior lo acoja.

\section{Obras citadas}

BOU, Enric: Papers privats. Assaig sobre les formes literàries autobiogràfiques, Barcelona, Edicions 62, 1993.

CABALLÉ, Anna: «Ego tristis (El diario íntimo en España)», Revista de Occidente, 182-183 (1996), pp. 99-120.

DIDIER, Béatrice: «El diario, ¿forma abierta?», Revista de Occidente, 182-183 (1996), pp. 39-47.

GONZÁLEZ, José Ramón (ed.): «Introducción», en José Jiménez Lozano. Nuestros Premios Cervantes, 3, Valladolid, Junta de Castilla y León/Universidad de Valladolid, 2003, pp. 15-21.

GRACIA, Jordi: Hijos de la razón. Contraluces de la libertad en las letras españolas de la democracia, Barcelona, Edhasa, 2001.

HIGUERO, Francisco Javier: La imaginación agónica de Jiménez Lozano, Barcelona, Anthropos, 1991.

JIMÉNEZ LOZANO, José: “La fiesta de los 'guardadores del pan'. Diálogo de un santo y dos filósofos", El Norte de Castilla (30 de marzo de 1958), p. 3. 
JIMÉNEZ LOZANO, José: Meditación española sobre la libertad religiosa, Barcelona, Destino, 1966.

JIMÉNEZ LOZANO, José: Historia de un otoño, Barcelona, Destino, 1971a.

JIMÉNEZ LOZANO, José: «El aporte del profesor Américo Castro a la interpretación del sentimiento religioso español», en Pedro Laín Entralgo, Estudios sobre la obra de Américo Castro, Madrid, Taurus, 1971b, pp. 209-246.

JIMÉNEZ LOZANO, José: El sambenito, Barcelona, Destino, 1972.

JIMÉNEZ LOZANO, José: La salamandra, Barcelona, Destino, 1973.

JIMÉNEZ LOZANO, José: El santo de mayo, Barcelona, Destino, 1976.

JIMÉNEZ LOZANO, José: Los cementerios civiles y la heterodoxia española, Madrid, Taurus, 1978.

JIMÉNEZ LOZANO, José: Los tres cuadernos rojos, Valladolid, Ámbito, 1986.

JIMÉNEZ LOZANO, José: Segundo abecedario, Barcelona, Anthropos, 1992.

JIMÉNEZ LOZANO, José: La luz de una candela, Barcelona, Anthropos, 1996.

JIMÉNEZ LOZANO, José: El cogedor de acianos, Barcelona, Anthropos, 1993.

JIMÉNEZ LOZANO, José: Los cuadernos de letra pequeña, Valencia, Pre-Textos, 2003.

JIMÉNEZ LOZANO, José: "Literatura con sabor a pan y leche", Entrevista realizada por Álvaro Movellán Fernández, Fábula, 15 (2004), pp. 5-59.

JIMÉNEZ LOZANO, José: Advenimientos, Valencia, Pre-Textos, 2006.

JIMÉNEZ LOZANO, José: Los cuadernos de Rembrandt, Valencia, Pre-Textos, 2010.

MAINER, José Carlos: De Posguerra (1951-1990), Barcelona, Grijalbo-Mondadori, 1994.

MEDINA-BOCOS, Amparo: «Claves para una lectura de José Jiménez Lozano», en Lea Bonnín (coord.), José Jiménez Lozano. Una narrativa y un pensamiento fieles a la memoria, Barcelona, Anthropos, 200, 2003, pp. 175-188.

MERINO BOBILLO, María: «Ideas que hacen escribir. Los comienzos de José Jiménez Lozano en los periódicos 1956-1969)», Comunicación y Sociedad, 2 (2010), pp. 149-178.

MERINO BOBILLO, María: Palabras que apuntan lejos. La obra de José Jiménez Lozano en la prensa, Madrid, Editorial Fragua, 2011a.

MERINO BOBILLO, María: «Síntoma de la imposición de los poderes en la sociedad contemporánea, según José Jiménez Lozano en La Razón», Comunicación y Hombre, 7 (2011b), pp. 183-193.

MORENO GONZÁLEZ, Santiago: «Libertad e inconformismo: sobre la concepción del relato de José Jiménez Lozano», Revista de Literatura, LXXII (2010), pp. 455-478.

POZUELO YVANCOS, José María [En línea], «La narrativa de Manuel Talens», Conferencia pronunciada en el Palacio de la Madraza el 8 de marzo de 2000 [Consultado: 5 de enero 2014]. Disponible en $\mathrm{http}: / /$ www.manueltalens.com/ensayos/narrativatalens.htm

TORTOSA, Virgilio: «La literatura púdica como una forma de intervención pública: el diario», Signa. Revista de la Asociación Española de Semiótica, 9 (2000), pp. 581-621. 